\title{
Probabilidade de Acontecimentos Envolvendo Aspetos Lógicos
}

\author{
Probability of Events Involving Logical Aspects
}

José António Fernandes*

\begin{abstract}
Resumo
Neste artigo estuda-se o conhecimento de Probabilidades de futuros professores dos primeiros anos escolares, quando na formulação dos acontecimentos estão envolvidos aspetos lógicos. Participaram no estudo 46 alunos da Licenciatura em Educação Básica, de uma Universidade do Norte de Portugal, os quais resolveram uma tarefa, com três itens, em contexto de avaliação formal: o primeiro sobre a probabilidade da reunião (conetivo ou), o segundo sobre a probabilidade conjunta (conetivo $e$ ) e o terceiro sobre a probabilidade condicionada, em que o acontecimento condicionado é, por sua vez, uma probabilidade conjunta (conetivo $e$ ). Em termos dos principais resultados do estudo, verificou-se que os alunos revelaram um desempenho muito limitado, trocando, frequentemente, os conetivos e e ou, a disjunção inclusiva com a disjunção exclusiva e na disjunção consideraram como sendo incompatíveis acontecimentos não disjuntos.
\end{abstract}

Palavras-chave: Probabilidades. Conetivos lógicos. Futuros professores dos primeiros anos.

\begin{abstract}
In this article, we study the Probability's knowledge of prospective primary school teachers, when there are logical aspects involved in the formulation of events. Forty-six students participated in the study, from a University in Northern Portugal, who had to resolve a three-item task in the context of a formal evaluation: the first one, on the union probability (connective or), the second one, on the joint probability (connective and), and the third one, on the conditional probability, in which the conditioned event is, in turn, a joint probability (connective and). In terms of the main results of the study, it was found that the students showed a very limited performance, frequently changing the connectives and and or, the inclusive disjunction with the exclusive disjunction and in the disjunction considered as incompatible non-disjoint events.
\end{abstract}

Keywords: Probability. Logical connectives. Prospective primary school teachers.

\section{Introdução}

Atualmente, o surgimento de um mundo cada vez mais assente na mudança, na incerteza e na previsão destaca o papel fundamental que as probabilidades desempenham nas sociedades contemporâneas, em oposição à permanência, à certeza e à previsibilidade de um mundo determinístico, que se vinha afirmando desde o Renascimento (FISCHBEIN, 1975).

Ora, nas últimas décadas, esta visão probabilística do mundo passou a ser incluída nos programas escolares dos primeiros anos de escolaridade de muitos países, incluindo também

\footnotetext{
* Doutor em Educação, Área de conhecimento de Metodologia do Ensino da Matemática pela Universidade do Minho, Portugal. Professor Associado no Instituto de Educação da Universidade do Minho, Portugal. Endereço para correspondência: Campus de Gualtar, 4710-057, Braga, Portugal. E-mail: jfernandes@ie.uminho.pt.
} 
Portugal (MINISTÉRIO DA EDUCAÇÃO E CIÊNCIA, 2013). Apesar dessa inovação, deve ter-se em conta que se trata de um primeiro passo que deve ser aprofundado. No caso português, quando é comparado o tempo sugerido no programa de Matemática para o tema de Organização e Tratamento de Dados, que inclui os temas de Probabilidade e Estatística, com outros temas (Números e operações, Geometria e Álgebra), conclui-se que é atribuído muito menos tempo àquele tema, menos de metade do tempo atribuído ao tema com o segundo menor tempo sugerido nesse programa (ALVES; FERNANDES, 2015).

Portanto, os dados referidos mostram que há, ainda, um caminho a percorrer para que as Probabilidades ocupem no currículo de Matemática um lugar compatível com a relevância social que, atualmente, lhe é conferida (FERNANDES, 2017).

A inclusão do tema de Probabilidades desde os primeiros anos de escolaridade tem sido defendida por muitos autores (e.g., BATANERO, 2013; BOROVCNIK; PEARD, 1996; FISCHBEIN, 1975) com o fundamento de que se trata de um domínio em que proliferam muitas ideias erróneas, as quais ao não serem contrariadas, de alguma forma, pelo ensino, se consolidariam com o avançar da idade e, em consequência, também do ensino (FISCHBEIN; SCHNARCH, 1997).

Naturalmente, a integração das Probabilidades nos programas escolares requer que os professores adquiram, na sua formação inicial e contínua, os conhecimentos que lhes permitam ensinar de forma adequada e eficiente esse tema. Neste caso, presentemente, os futuros professores dos primeiros anos de escolaridade ${ }^{1}$ têm, geralmente, ao longo da sua formação inicial, no ensino superior, uma disciplina semestral sobre Probabilidades e Estatística.

Assim, face às necessidades de formação em Probabilidade dos futuros professores dos primeiros anos escolares, neste estudo investigam-se os seus conhecimentos na determinação de probabilidades de acontecimentos em cuja formulação se destacam aspetos lógicos, designadamente os conetivos e e ou, aplicados à probabilidade conjunta, à probabilidade da reunião e à probabilidade condicionada.

No caso da probabilidade condicionada, Watson (1995) defende que ela se deve introduzir mais cedo no currículo escolar, concretamente ao nível do $3 .^{\circ}$ ciclo do ensino básico e do ensino secundário, pois trata-se de um conceito útil para desenvolver o uso de linguagem e para interpretar situações condicionadas com origem exterior à matemática.

\footnotetext{
${ }^{1}$ Em Portugal, o ensino básico desenvolve-se entre o $10^{\circ}$ e o $9 .^{\circ}$ ano de escolaridade, e organiza-se nos três seguintes ciclos: $1 .^{\circ}$ ciclo, do $1 .^{\circ}$ ao $4 .^{\circ}$ ano; $2 .^{\circ}$ ciclo, $5 .^{\circ}$ e $6 .^{\circ}$ anos; e $3 .^{\circ}$ ciclo, do $7 .^{\circ}$ ao $9 .^{\circ}$ ano. Os futuros professores a que nos referimos neste artigo podem lecionar ao nível do $1 .^{\circ}$ e $2 .^{\circ}$ ciclos.
} 
Nas secções seguintes, apresenta-se o enquadramento teórico do estudo, o método de pesquisa, a apresentação dos resultados obtidos no estudo e, por fim, as principais conclusões e implicações do estudo.

\section{Enquadramento teórico}

Nesta secção referir-nos-emos ao marco teórico do estudo e à investigação prévia realizada no âmbito da problemática aqui estudada.

\subsection{Marco teórico}

Godino e colaboradores, no modelo do Enfoque Ontossemiótico do conhecimento e instrução matemática (GODINO, 2009; GODINO; BATANERO; FONT, 2007), assumem que o conhecimento resulta das práticas matemáticas (operativas e discursivas) que o sujeito realiza para resolver uma situação-problema, para comunicar a outros a solução ou validar a solução e generalizá-la a outros problemas e contextos. Essas práticas apresentam um caráter dual, podendo o seu significado ser considerado de um ponto de vista institucional (no nosso caso, a escola, os professores e os manuais escolares) ou de um ponto de vista pessoal (uma pessoa que enfrenta uma situação-problema, como seja um aluno) (GODINO; BATANERO, 1994).

Para além da dualidade institucional-pessoal, antes referida, no Enfoque Ontossemiótico reconhecem-se outras dualidades (GODINO; BATANERO; FONT, 2007), das quais é, também, relevante para o nosso estudo a dualidade expressão-conteúdo, que permite confrontar os significados dos objetos que intervêm nas funções semióticas (entendidas como correspondências estabelecidas por uma pessoa ou instituição entre um antecedente, expressão, e um consequente, conteúdo) com os significados institucionais de referência. Nesse processo de comparação, a verificação de discrepâncias entre esses significados, ou seja, entre os significados institucional e pessoal (GODINO; BATANERO, 1994), conduz à identificação de conflitos semióticos.

Em Godino (2009) reconhece-se que o conhecimento para ensinar é um conhecimento complexo e multifacetado, identificando-se uma diversidade de facetas desse conhecimento, que se referem a seguir: epistémica, que se refere aos conhecimentos matemáticos do contexto institucional em que se realiza o processo de estudo, como sejam a escola, os professores e os manuais escolares, nos diversos componentes do conteúdo (problemas, linguagens, 
procedimentos, definições, propriedades e argumentos); cognitiva, que se refere aos conhecimentos pessoais dos alunos e à progressão das suas aprendizagens; afetiva, que diz respeito aos estados afetivos (atitudes, emoções, crenças e valores) dos alunos em relação aos objetos matemáticos e ao processo de estudo seguido; mediacional, que é relativa aos recursos educativos, com destaque para as tecnologias de informação e comunicação, e à gestão do tempo nas distintas ações e processos de estudo; interacional, que se refere aos padrões de interação entre os alunos e entre o professor e os alunos para o estabelecimento e negociação de significados; ecológica, que se refere às relações do processo de estudo com o contexto social, político e económico, que o suportam e condicionam.

Este estudo centra-se nas facetas epistémica e cognitiva, que são as facetas-chave da formação do professor na perspetiva do Enfoque Ontossemiótico (GODINO, 2009), em que se postula para elas um ponto de vista antropológico e semiótico, em que a atividade humana adquire significado a partir das ações das pessoas para resolver situações-problema com que se deparam.

\subsection{Investigação prévia}

Em geral, em muitos países, em que se inclui também Portugal, a formação dos professores para ensinar Probabilidades e Estatística apresenta debilidades, não sendo considerada adequada para promover um ensino e uma aprendizagem de acordo com as orientações atuais. No contexto brasileiro, Costa e Nacarato (2011, p. 376) constataram que dos professores de Matemática em exercício no ensino básico e secundário, envolvidos no seu estudo, a maioria referiu ter tido, na sua graduação, formação em Estatística, mas poucos em Probabilidades. No caso da formação contínua, nenhum professor referiu ter tido qualquer formação em Probabilidades, salientando-se uma formação "a partir da experiência e de consultas a materiais diversos, em especial, o livro didático". Essa formação limitada foi, também, afirmada pelos professores que nas universidades eram responsáveis pela formação dos futuros professores nessas disciplinas.

Tal como em outros temas matemáticos, também no caso das Probabilidades, a compreensão da linguagem usada em diferentes fases da exploração de tarefas, designadamente ao nível do enunciado das tarefas, do processo de resolução e da comunicação de resultados, é um aspeto decisivo no sucesso da determinação de probabilidades de acontecimentos. 
Segundo Watson (2005), tradicionalmente, sugere-se no currículo escolar o ensino de probabilidades numa vertente de matemática pura, com situações limitadas a espaços amostrais finitos em que se pode listar, contar e comparar resultados de forma explícita. Considerando importante essa abordagem, a autora advoga, também, a exploração de situações inseridas em contextos sociais, em que os espaços amostrais são de natureza mais difusa, não são explicitamente referidos, não envolvem necessariamente números e onde se salientam questões de linguagem e interpretação probabilística.

Tversky e Kahneman (1982a) foram pioneiros no estudo de situações probabilísticas em contextos públicos, como sejam os meios de comunicação social, nos quais são especialmente relevantes as questões de linguagem. Nos seus muitos estudos, com estudantes universitários, estes autores concluíram que os sujeitos recorriam ao uso de heurísticas e aderiam a raciocínios causais (TVERSKY; KAHNEMAN,1982b) e à falacia da conjunção (TVERSKY; KAHNEMAN, 1983) na avaliação de probabilidades. As heurísticas, apesar de úteis em muitos situações, revelam-se limitadas em outras pois, enquanto estratégias simplificadoras das situações, elas poderão não captar aspetos que são essenciais para a resolução dessas situações.

No caso dos raciocínios causais, tal como Tversky e Kahneman (1982b), também Pollatsek et al. (1987) obtiveram evidência acerca da prevalência das inferências de efeitos a partir de causas. Mais concretamente, esses autores concluíram que as dificuldades de avaliação de probabilidades condicionadas resultavam de dificuldades de tradução do enunciado para uma simbologia adequada, e avançaram que o maior erro de tradução podia ter resultado da confusão entre as probabilidades condicionada e conjunta, isto é, entre $P(A \mid B)$ e $P(A \cap B)$. Segundo esses mesmos autores, o facto de as pessoas disporem de algum esquema que integre acontecimentos do mundo real parece diminuir os erros de tradução e a maior discrepância entre os valores de $P(A \mid B)$ e $P(B \mid A)$, isto é, entre a probabilidade condicional e a sua transposta, permitiu melhorar a realização dos sujeitos nesses problemas.

Finalmente, a adesão à falácia da conjunção significa que os estudantes avaliam a probabilidade da conjunção como sendo mais provável do que a probabilidade de qualquer dos acontecimentos que a constituem, violando, assim, a lei da extensão que afirma que $P(A \cap B) \leq P(A)$ e $P(A \cap B) \leq P(B)$. Este fenómeno ocorre, sobretudo, quando um dos acontecimentos é altamente representativo do outro, como acontece com o acontecimento $\mathrm{Um}$ ser humano nasceu em África, que é altamente representativo do acontecimentos Um ser humano é de cor negra. Em consequência, os sujeitos tendem a afirmar que o acontecimento Um ser 
humano é de cor negra e nasceu em África é mais provável do que o acontecimento Um ser humano é de cor negra (FERNANDES, 1990).

Ao nível dos enunciados das tarefas probabilísticas, elas podem revelar-se mais ou menos explícitas em termos do seu propósito, isto é, daquilo que se pretende obter com tais tarefas. Por exemplo, no universo dos portugueses, são equivalentes as afirmações Que um português seja professor, sabendo que é mulher e Que uma mulher seja professora, portanto, são também equiprováveis, mas a probabilidade condicionada é formulada de forma explícita na primeira afirmação e de forma implícita na segunda.

Entre esses dois tipos de formulação, a implícita revela-se mais difícil ao requerer que o aluno reconheça o tipo de probabilidade que nela está envolvida. A esse respeito, um estudo de Fernandes et al. (2015), em que participaram futuros professores dos primeiros anos, tal como acontece no presente estudo, confirmou que a determinação de probabilidades conjuntas e condicionadas de afirmações implícitas se revelou muito mais difícil do que no caso das afirmações explícitas.

Também, Watson e Moritz (2002), num estudo envolvendo tarefas em contextos sociais e alunos de vários níveis escolares, do ensino primário, secundário e recémmatriculados na universidade, verificou-se que as questões lógicas e de linguagem associadas à conjunção de acontecimentos são difíceis para os alunos do $3 .^{\circ}$ ciclo do ensino básico, antecipando, ainda, dificuldades dos alunos quando é requerida a transferência do que aprenderam em pequenos espaços amostrais bem definidos para contextos sociais mais complexos e difusos.

Watson e Moritz (2003), em outro estudo, investigaram, ao longo de vários anos, a compreensão da linguagem do acaso de alunos do $5 .^{\circ}$ ao $11 .^{\circ}$ ano, recorrendo, para tal, a duas tarefas: uma relativa à avaliação e localização na escala $[1,0]$ das chances de realização de vários acontecimentos e outra sobre a interpretação de um enunciado envolvendo um valor de probabilidade em percentagem. Em ambas as tarefas se verificou um aumento de respostas corretas com o ano de escolaridade, sendo que, na primeira tarefa, a percentagem de alunos que avaliaram de forma limitada ou não avaliaram as afirmações variou entre $20 \%\left(10 .^{\circ}\right.$ ano) e $46 \%$ ( $6 .^{\circ}$ ano) e, na segunda tarefa, a percentagem de alunos que interpretaram de forma vaga ou inapropriada variou entre $0 \%\left(11 .^{\circ}\right.$ ano) e $44 \%\left(5 .^{\circ}\right.$ ano).

Apesar de as maiores dificuldades sentidas pelos alunos na determinação de probabilidades no caso das afirmações implícitas, essas situações probabilísticas devem ser exploradas pelos alunos e, consequentemente, também na formação dos professores, pois elas 
revestem-se de uma grande importância formativa, designadamente ao nível da literacia probabilística (WATSON; MORITZ, 2003).

Independentemente de se tratar de afirmações explícitas ou implícitas, em relação à probabilidade em questão, a determinação da probabilidade de acontecimentos compostos implica a compreensão e aplicação sistemática dos conetivos lógicos $e$, ou e não, seja de forma isolada ou combinada. Donde, à exceção do cálculo de probabilidades de acontecimentos simples, conclui-se que a determinação de probabilidades está intimamente ligada à correta interpretação e aplicação desses conetivos.

Num estudo que incluiu a classificação de acontecimentos em certos, possíveis (mas não certos) e impossíveis, Fernandes (1999) concluiu que as maiores dificuldades dos alunos do $8 .^{\circ}$ ano e $11 .^{\circ}$ ano, que participaram no estudo, se verificaram nos acontecimentos envolvendo conetivos lógicos. Em termos mais detalhados, segundo o autor,

As maiores discrepâncias entre os alunos do $8 .^{\circ}$ ano e do $11 .^{\circ}$ ano observaram-se nos acontecimentos certos e/ou que envolviam conectivos lógicos na sua formulação, precisamente aqueles que se revelaram mais difíceis, nos quais os alunos do $11^{\circ}$ ano selecionaram mais frequentemente a resposta correta (FERNANDES, 1999, p. 285).

Neste trabalho pretende-se ampliar o estudo realizado sobre a classificação de acontecimentos, considerando, agora, a probabilidade da reunião, a probabilidade conjunta e a probabilidade condicionada de acontecimentos em que se destacam os conetivos lógicos $e$ e ou.

\section{Método}

Neste artigo estuda-se o conhecimento de futuros professores dos primeiros anos escolares sobre Probabilidades, em situações em que estão envolvidos conetivos $e$ e ou, a probabilidade da reunião, a probabilidade conjunta e a probabilidade condicional.

Participaram no estudo 46 alunos do curso de Licenciatura em Educação Básica, de uma universidade do Norte de Portugal, curso que dá acesso a cursos de mestrado dirigidos à Educação de Infância e/ou aos primeiros anos de ensino, até ao $2 .^{\circ}$ ciclo do ensino básico. Esses alunos, à entrada na Universidade, eram detentores de uma formação matemática muito variada, desde aqueles que terminaram o estudo da matemática no $9 .^{\circ}$ ano do ensino básico (23,9\%), no curso Científico-Tecnológico (17,4\%), no curso de Ciências Socias (34,8\%) ou num curso profissional $(23,9 \%)$. Todos os alunos afirmaram ter sentido alguma dificuldade nas disciplinas de Matemática que frequentaram na Universidade, especificamente 30,4\% 
afirmaram ter muita dificuldade, $47,8 \%$ afirmaram ter dificuldades e $21,8 \%$ afirmaram ter pouca dificuldade.

Num contexto de avaliação formal, foram aplicadas aos alunos quatro tarefas de Probabilidades, das quais é estudada, aqui, apenas uma (Quadro 1). Geralmente, no contexto escolar, na resolução dessa tarefa recorre-se à representação dos conjuntos correspondentes aos acontecimentos num diagrama de Venn, conectando, assim, as Probabilidades com a lógica da teoria de conjuntos.

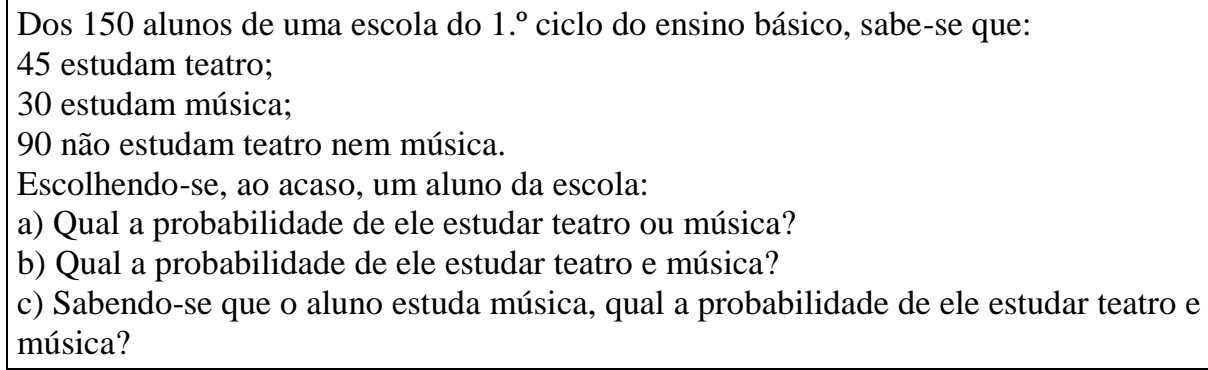

Quadro 1 - Tarefa proposta aos alunos Fonte: Autor (2016).

Em termos de conetivos lógicos e das probabilidades implicadas nos diferentes itens da tarefa, tem-se: em a) é usado o conetivo ou, que se traduz na probabilidade da reunião de dois acontecimentos; em b) é usado o conetivo $e$, que se traduz na probabilidade da interseção de dois acontecimentos, ou seja, da probabilidade conjunta; e em c) solicita-se a determinação de uma probabilidade condicionada, em que num dos acontecimentos é usado o conetivo $e$, que se traduz na interseção de dois acontecimentos.

Em termos de análise de dados, em cada um dos itens da tarefa, classificaram-se as respostas dos alunos em corretas e incorretas, determinando-se a percentagem de cada categoria, bem como de não respostas. Seguidamente, a partir das respostas incorretas, estudaram-se as dificuldades e erros dos alunos, ou seja, os conflitos semióticos, em cada um dos itens. Essa análise, realizada através da análise de conteúdo das respostas dos alunos, permitiu definir diferentes categorias, cada uma das quais abrangendo as respostas alicerçadas numa mesma ideia comum e que são referidas na próxima secção, aquando da análise de dados.

\section{Apresentação de resultados}

Nesta secção começa-se por apresentar as respostas dos alunos à tarefa proposta, considerando os tipos de resposta (correta e incorreta) e incluindo, também, as não respostas. 
Seguidamente, a partir das respostas incorretas, estudam-se as dificuldades e erros manifestados pelos alunos na resolução da tarefa.

\subsection{Tipos de respostas dos alunos}

Relativamente à tarefa proposta, considerando os acontecimentos M: estudar música e T:estudar teatro, tem-se a representação em diagrama de Venn dos vários acontecimentos envolvidos (Figura 1) e uma possível resolução de cada um dos itens:

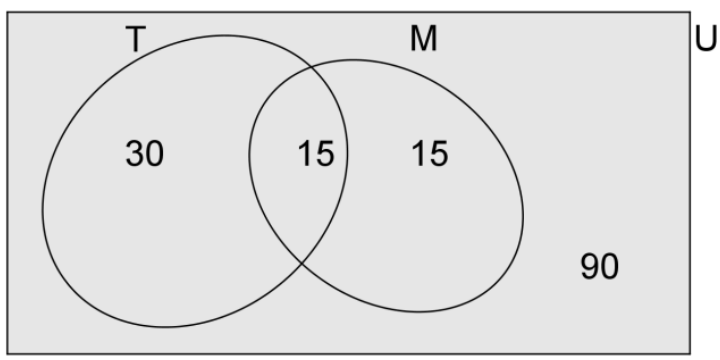

Figura 1 - Representação dos acontecimentos em diagrama de Venn Fonte: Dados da pesquisa organizados pelo autor (2017).

a) $P(T \cup M)=1-P(\bar{T} \cap \bar{M})=1-90 / 150=60 / 150=2 / 5$;

b) Como $\#(T \cap M)=\# T+\# M-\#(T \cup M)=45+30-60=15, P(T \cap M)==$ $15 / 150=1 / 10 ;$

c) $P[(T \cap M) \mid M]=P[(T \cap M) \cap M] / P(M)=P(T \cap M) / P(M)=(1 / 10) /(30 /$ 150) $=1 / 2$.

$\mathrm{Na}$ Tabela 1 apresentam-se as frequências (percentagens) dos diferentes tipos de resposta e de não respostas em cada um dos itens da tarefa proposta.

Tabela 1 - Frequências (percentagens) dos diferentes tipos de resposta e não respostas nos itens da tarefa

\begin{tabular}{lccc}
\hline & \multicolumn{3}{c}{ Itens } \\
\cline { 2 - 4 } Tipo de resposta & $\mathrm{a})$ & $\mathrm{b})$ & $\mathrm{c})$ \\
\hline Correta & $8(17,4)$ & $20(43,5)$ & $9(19,6)$ \\
Incorreta & $34(73,9)$ & $21(45,6)$ & $30(65,2)$ \\
Não resposta & $4(8,7)$ & $5(10,9)$ & $7(15,2)$ \\
\hline \multicolumn{4}{c}{} \\
\cline { 2 - 4 }
\end{tabular}

Recorrendo aos dados da Tabela 1, conclui-se que na globalidade dos três itens se obteve apenas 26,8\% respostas corretas, enquanto se registaram 61,6\% respostas incorretas e $11,6 \%$ não respostas. Essas percentagens mostram que os alunos sentiram muitas dificuldades na resolução da tarefa.

As dificuldades dos alunos manifestaram-se em todos os itens, pois em todos eles foi sempre superior a percentagem de respostas incorretas, claramente mais acentuadas no item a) 
$(73,9 \%)$ e no item c) $(65,2 \%)$. Já no item b) obteve-se uma percentagem de respostas corretas $(43,5 \%)$ mais próxima da percentagem de respostas incorretas $(45,6 \%)$.

Considerando as probabilidades que são pedidas em cada um dos itens, verifica-se que se revelou mais difícil a determinação da probabilidade da disjunção, no item a), e da probabilidade condicionada, no item c), enquanto a determinação da probabilidade conjunta, pedida no item $b$ ), foi mais sucedida.

É possível que a maior dificuldade dos alunos na probabilidade da reunião se explique pelo facto de na disjunção o aluno ter de decidir entre a disjunção inclusiva e a disjunção exclusiva, o que não acontece no caso da conjunção. Essa explicação confirmou-se empiricamente nas resoluções dos alunos pois, como veremos aquando do estudo dos erros, foram bastantes os alunos que confundiram a disjunção inclusiva com a disjunção exclusiva.

Seguidamente, estudando as dificuldades e erros manifestados pelos alunos nas suas resoluções, esclarecem-se as razões do melhor desempenho dos alunos na probabilidade conjunta do que na probabilidade da reunião e condicional.

\subsection{Dificuldades e erros dos alunos}

Nesta subsecção analisam-se as respostas erradas dos alunos em cada um dos itens, com o objetivo de identificar as dificuldades e os erros por eles manifestados nas suas resoluções.

\section{Item a)}

No item a) questionam-se os alunos sobre a determinação de uma probabilidade da reunião, que envolve a disjunção de dois acontecimentos, encontrando-se registados na Tabela 2 os tipos de erros cometidos pelos alunos.

Tabela 2 - Frequências (percentagens) das dificuldades e erros dos alunos no item a)

\begin{tabular}{lc}
\hline Tipo de erro & Frequências (\%) \\
\hline $\begin{array}{l}\text { Considerar os acontecimentos implicados na disjunção como sendo } \\
\text { disjuntos ou incompatíveis }\end{array}$ & $22(47,8)$ \\
$\begin{array}{l}\text { Não incluir na disjunção os alunos que estudam teatro e música } \\
\text { simultaneamente }\end{array}$ & $6(13,0)$ \\
$\begin{array}{l}\text { Uso inadequado de terminologia } \\
\text { Identificar corretamente os acontecimentos mas não determinar a } \\
\text { probabilidade }\end{array}$ & $3(6,5)$ \\
$\begin{array}{l}\text { Determinar as probabilidades sem as combinar } \\
\text { Não inteligível }\end{array}$ & $1(2,2)$ \\
\hline
\end{tabular}

Fonte: Dados da pesquisa organizados pelo autor (2017). 
Conforme foi já referido (ver Tabela 1), esse item revelou-se o mais difícil de todos, com menos de $20 \%$ de alunos a responderem corretamente. De entre as dificuldades dos alunos, salienta-se o considerar os acontecimentos como sendo incompatíveis ou disjuntos $(47,8 \%)$, o que em termos de conetivos lógicos corresponde a considerar a conjunção como sendo um acontecimento impossível, como se ilustra na Figura 2.

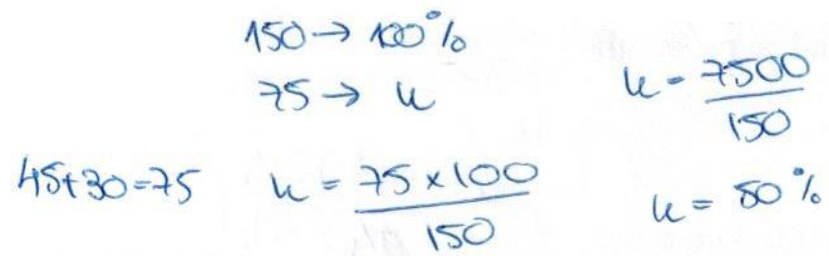

Figura 2 - Resolução do item a) pelo aluno A10 Fonte: Resposta do aluno (2016).

Pela Figura 2 verificamos que o aluno A10 ao adicionar 45 com 30 está a incluir no total de casos favoráveis duas vezes número de alunos que estudam teatro e música simultaneamente. Ora, tal relação apenas se verifica quando os dois acontecimentos são incompatíveis, o que não acontece na situação apresentada.

Seguidamente, com muitos menos alunos $(13,0 \%)$, observou-se o erro de não incluir na disjunção os alunos que estudam teatro e música simultaneamente, conforme se exemplifica na Figura 3.

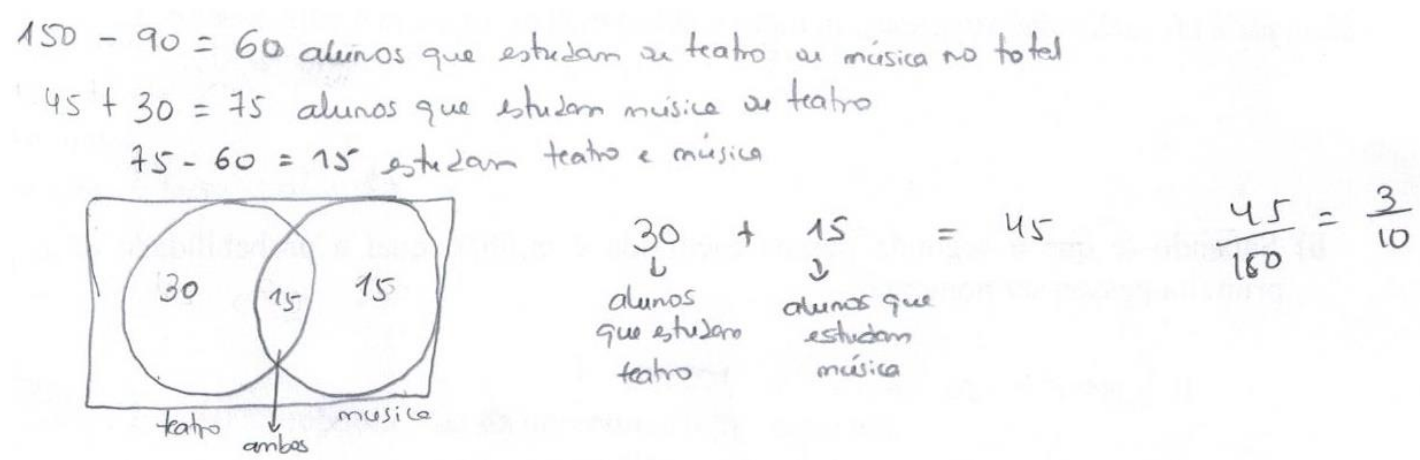

Figura 3 - Resolução do item a) pelo aluno A6 Fonte: Resposta do aluno (2016).

Neste caso, tal como A6, todos os alunos, em termos de conetivos lógicos, confundiram a disjunção inclusiva com a disjunção exclusiva. Esse erro pode ter origem no uso da disjunção em situações da linguagem corrente, onde frequentemente é usada enquanto disjunção exclusiva.

O uso inadequado de terminologia foi referido por poucos alunos $(6,5 \%)$ e consistiu no uso impróprio de operações entre conjuntos, como se mostra na Figura 4. 


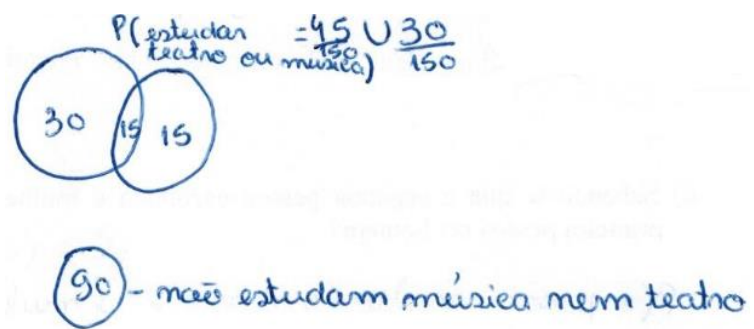

Figura 4 - Resolução do item a) pelo aluno A31. Fonte: Resposta do aluno (2016).

Esses alunos, tal como o A31, em vez de considerarem a operação de adição estabeleceram a operação de reunião entre números, o que traduz uma dificuldade clara dos alunos no uso dessas operações. Observa-se, ainda, que também esses alunos não têm em consideração que alguns alunos estudam simultaneamente teatro e música, tal como foi referido anteriormente.

Nos dois outros tipos de erros, um aluno identificou corretamente os conjuntos em questão através de um diagrama de Venn, mas não determinou a probabilidade pedida, e outro aluno determinou a probabilidade de estudar teatro e a probabilidade de estudar música, mas não as combinou para obter a probabilidade de estudar teatro ou música.

\section{Item $b$ )}

No item b) questionam-se os alunos sobre a determinação de uma probabilidade conjunta, que envolve a conjunção de dois acontecimentos, encontrando-se registados na Tabela 3 os tipos de erros cometidos pelos alunos.

Tabela 3 - Frequências (percentagens) das dificuldades e erros dos alunos no item b)

\begin{tabular}{lc}
\hline Tipo de erro & Frequências (\%) \\
\hline Confundir conjunção com disjunção & $12(26,1 \%)$ \\
Identificar corretamente os acontecimentos mas não determinar a & $3(6,5 \%)$ \\
probabilidade & $2(4,3 \%)$ \\
Uso inadequado de terminologia & $1(2,2 \%)$ \\
Determinar as probabilidades sem a combinar & $1(2,2 \%)$ \\
Considerar os acontecimentos independentes & $2(4,3 \%)$ \\
Não inteligível &
\end{tabular}

Esse foi o item que se revelou menos difícil para os alunos (ver Tabela 1), com cerca de metade a responderem corretamente. De entre os erros cometidos pelos alunos, destaca-se a confusão da conjunção com a disjunção $(26,1 \%)$, cuja exemplificação se mostra na Figura 5.

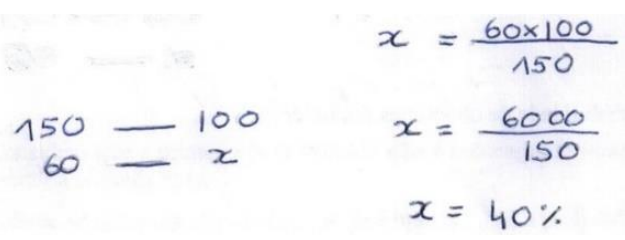

Figura 5 - Resolução do item b) pelo aluno A14 Fonte: Resposta do aluno (2016). 
O aluno A14, apesar de ter considerado erradamente a disjunção, determinou-a corretamente, retirando o número de alunos que estudam simultaneamente teatro e música aquando da resolução do item a). Desses alunos, mais quatro procederam de modo análogo, enquanto os restantes sete não retiraram os alunos que estudam simultaneamente teatro e música, o que equivale a considerar esses alunos duas vezes no número de casos favoráveis.

Poucos alunos $(6,5 \%)$ identificaram o número de casos favoráveis ao acontecimento conjunção, mas não continuaram com a determinação da probabilidade pedida, como se mostra na Figura 6.

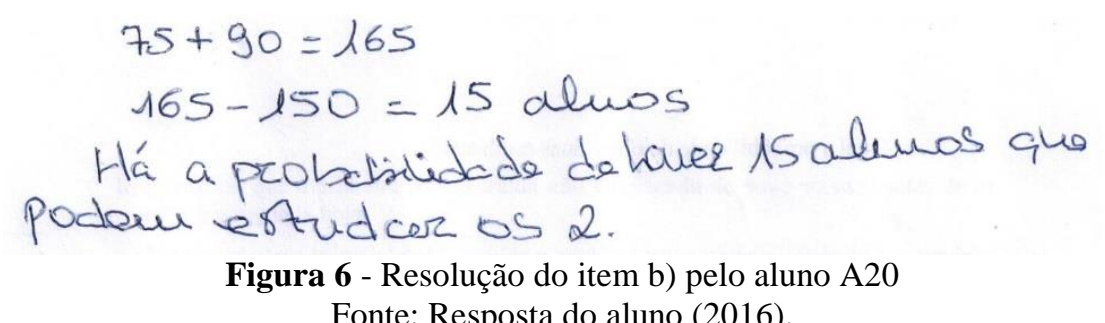

O aluno A20 determina corretamente que são quinze os alunos que estudam simultaneamente teatro e música, porém não determina a probabilidade correspondente e termina aqui a sua resolução.

Comparativamente com o item anterior, nesse item menos alunos (4,3\%) usaram inadequadamente terminologia. Na Figura 7 ilustra-se o uso inadequado da terminologia por parte desses alunos.

\section{$P($ estudar teatro e músiea $)=45 \cap 30$}

Figura 7 - Resolução do item b) pelo aluno A40

Fonte: Resposta do aluno (2016).

Tal como no item anterior, o aluno A40 considera erradamente a operação de interseção em vez da operação de adição, o número de elementos de cada acontecimento em vez das probabilidades e, também, não retira o número de alunos que estudam simultaneamente teatro e música.

Por fim, um aluno determina corretamente cada uma das probabilidades dos acontecimentos intervenientes na conjunção sem as combinar e outro aluno multiplica essas probabilidades, considerando, assim, que os acontecimentos são independentes.

Item $c$ )

No item c) questionam-se os alunos sobre a determinação de uma probabilidade condicionada, em que um dos acontecimentos implicados na probabilidade condicionada envolve a conjunção de acontecimentos. Na Tabela 4 encontram-se registados os diferentes tipos de erros cometidos pelos alunos. 
Tabela 4 - Frequências (percentagens) das dificuldades e erros dos alunos no item c)

\begin{tabular}{lc}
\hline Tipo de erro & Frequências $(\%)$ \\
\hline $\begin{array}{l}\text { Confundir conjunção com disjunção na determinação da } \\
\text { probabilidade condicionada }\end{array}$ & $15(32,6)$ \\
Confundir probabilidade da disjunção com probabilidade & $9(19,6)$ \\
condicionada & $3(6,5)$ \\
Confundir probabilidade conjunta com probabilidade condicionada & $3(6,5)$ \\
Não inteligível & \\
\hline
\end{tabular}

Fonte: Dados da pesquisa organizados pelo autor (2017).

Esse item também se revelou muito difícil para os alunos, tendo apenas $20 \%$ respondido corretamente (ver Tabela 1). De entre os vários erros cometidos pelos alunos, salienta-se a confusão entre a conjunção e a disjunção na determinação da probabilidade condicionada $(32,6 \%)$, como se exemplifica na Figura 8.

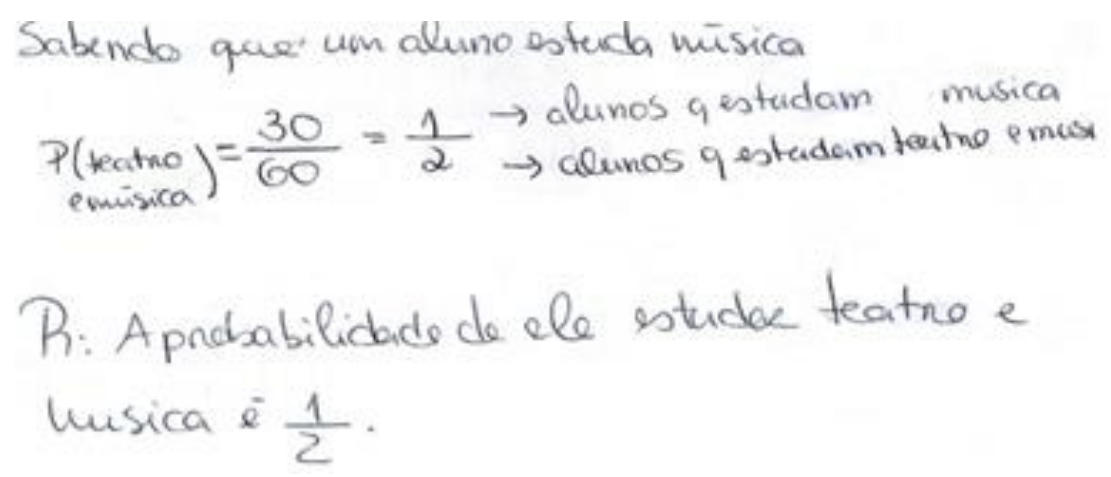

Figura 8 - Resolução do item c) pelo aluno A28 Fonte: Resposta do aluno (2016).

A resposta do aluno A28, embora esteja correto o valor da probabilidade (1/2), apresenta vários erros, como seja considerar o número de alunos que estudam música, o número de alunos que estudam teatro ou música (que ele afirma como sendo o número de alunos que estudam teatro e música) e a inversão dos termos da razão da probabilidade condicionada. Nesse último caso, depois de ter substituído a conjunção pela disjunção, esse e outro aluno terão determinado a probabilidade da condicional transposta ao considerar a probabilidade de estudar música, sabendo que estuda teatro ou música.

Tal como se verificou nos itens anteriores, três desses alunos, além de confundirem a conjunção com a disjunção, também consideraram os acontecimentos implicados na disjunção como sendo disjuntos, ou seja, não retiraram os alunos que estudam teatro e música simultaneamente.

Considerando a probabilidade condicionada como a razão entre o número de casos favoráveis e de casos possíveis, portanto na perspetiva de restrição do espaço amostral, verificou-se que cinco alunos apresentaram corretamente apenas o número de casos 
favoráveis (15) e três alunos apresentaram corretamente apenas o número de casos possíveis (30).

Também, um número considerável de alunos (19,6\%) confundiu a probabilidade da disjunção com a probabilidade condicionada, como se exemplifica na Figura 9.

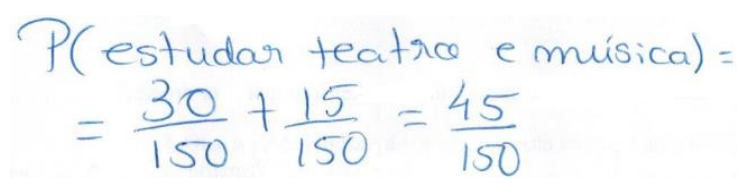

Figura 9 - Resolução do item c) pelo aluno A29 Fonte: Resposta do aluno (2016).

O aluno A29 ao determinar a probabilidade da disjunção retira os alunos que estudam teatro e música simultaneamente, tal como se verificou no item a), o que equivale a interpretar o conetivo da disjunção inclusiva como de disjunção exclusiva. À exceção de um, todos esses alunos cometeram esse erro.

Finalmente, alguns alunos (6,5\%) também confundiram a probabilidade conjunta com a probabilidade condicionada, como se mostra na Figura 10.

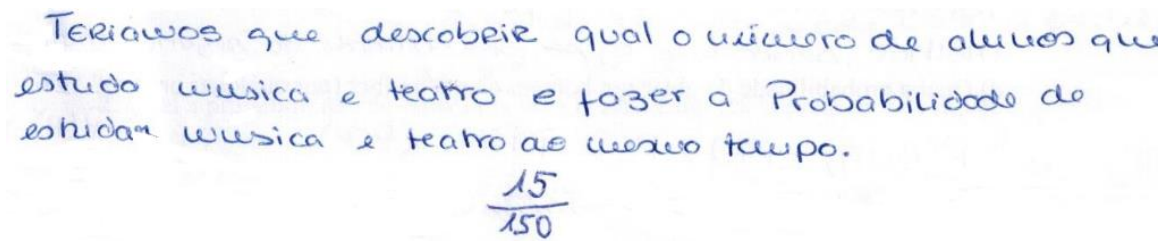

Figura 10 - Resolução do item c) pelo aluno A4 Fonte: Resposta do aluno (2016).

O aluno 4 determina corretamente a probabilidade de estudar teatro e música simultaneamente, o que acontece também com mais dois alunos, dos quais um repete mesmo a resposta dada ao item b). Ao dar a mesma resposta aos itens b) e c), esse último aluno reforça a não distinção entre a probabilidade conjunta e a probabilidade condicionada, que eram pedidas nesses itens.

No conjunto dos três itens da tarefa verificou-se, ainda, que seis alunos $(13,0 \%)$ ) deram como resposta da probabilidade pedida um valor superior a 1 , denotando, assim, o desconhecimento de uma das propriedades fundamentais do conceito de probabilidade, a qual estabelece que a probabilidade de qualquer acontecimento é um valor do intervalo $[0,1]$.

Já em termos de estratégia de determinação das probabilidades, embora se tenha verificado que a representação das probabilidades através de razões foi largamente maioritária no conjunto dos três itens, houve um número razoável de alunos, dezoito $(39,1 \%)$, que representaram as probabilidades sob a forma de percentagem, recorrendo, para tal, à regra de três simples para determinar essas probabilidades. 


\section{Conclusões e implicações}

Os resultados do estudo realizado mostram que os alunos tiveram um desempenho muito limitado nos itens da tarefa, muito inferior ao obtido pelos alunos do $8 .^{\circ}$ e $11 .^{\circ}$ anos de escolaridade na classificação de acontecimentos do estudo de Fernandes (1999).

A inclusão dos conetivos lógicos na formulação dos acontecimentos constituiu um aspeto que levou muitos alunos a responderem incorretamente ao longo dos três itens da tarefa. Entre as dificuldades dos alunos, salientou-se a confusão entre a interseção e a reunião de dois acontecimentos, a consideração da reunião de dois acontecimentos como sendo disjuntos, quando na realidade não o eram, e excluir da reunião de dois acontecimentos a sua interseção, quando de facto ela não era vazia. Tal como os futuros professores dos primeiros que participaram neste estudo, também alunos do $3 .^{\circ}$ ciclo sentiram dificuldades em questões lógicas e de linguagem associadas à conjunção de acontecimentos no estudo de Watson e Moritz (2002).

No caso da probabilidade condicionada, para além da confusão entre interseção e reunião de acontecimentos, manifestada pelos alunos, verificou-se, também, que alguns deles consideraram a probabilidade condicional como sendo a probabilidade da reunião ou da interseção de acontecimentos. Enquanto a confusão entre a probabilidade condicionada e a probabilidade conjunta é um erro referido na literatura (e.g., FERNANDES et al., 2014; POLLATSEK et al., 1987; WATSON; MORITZ, 2002), o mesmo não acontece com a confusão entre a probabilidade condicionada e a probabilidade da reunião, que constitui um resultado novo deste estudo. Possivelmente, essa última dificuldade, entre a probabilidade condicionada e a probabilidade da reunião, terá estado ligada à confusão entre a interseção e a reunião de acontecimentos, dificuldade que foi transversal aos três itens da tarefa, e que explicaria a menor adesão dos alunos à confusão entre probabilidade condicional e probabilidade conjunta. Refira-se ainda, por último, que a troca da probabilidade condicionada com a sua transposta ocorreu apenas pontualmente.

Finalmente, com menor incidência, observaram-se, ainda, dificuldades dos alunos no uso de terminologia, em combinar as probabilidades dos acontecimentos para obter a probabilidade da reunião e da interseção e em considerar que a probabilidade de qualquer acontecimento não pode tomar um valor superior a 1. Essas dificuldades dos alunos traduzem uma visão muito limitada e primitiva do conceito de probabilidade, que também foi observada por Fernandes et al. (2014) em alunos futuros professores dos primeiros anos. 
Uma compreensão muito limitada do conceito de probabilidade foi, também, referida nos estudos de Silva (2011) e de Cavalcante, Andrade e Régnier (2016), envolvendo alunos futuros professores de Matemática do ensino básico e secundário, sobretudo no que respeita à integração das diferentes facetas do conhecimento que intervêm no ato de ensinar (Godino, 2009).

Assim, as muitas e variadas dificuldades e erros manifestados pelos alunos no presente estudo implicam a necessidade de aprofundar a formação desses futuros professores dos primeiros anos em Probabilidades, se pretendemos que eles desenvolvam um ensino de qualidade com as crianças. Particularmente, as questões lógicas e de linguagem devem ser enfatizadas no âmbito das Probabilidades e também noutras disciplinas, até porque se trata de uma temática de interesse em diferentes domínios científicos.

No caso das Probabilidades, esse aprofundamento pode passar pela inclusão dos conetivos lógicos $e$, ou e não na formulação dos acontecimentos probabilísticos, como acontece na tarefa aqui explorada, e das correspondentes operações de conjuntos, pela exploração dessas situações probabilísticas e pela discussão e reflexão, em grupo turma, das resoluções dos alunos. Adicionalmente, podem-se propor tarefas em que são dados os valores de probabilidade e se pede aos alunos que estabeleçam os respetivos acontecimentos com recurso aos conetivos lógicos. Comparativamente com as tarefas que partem dos conetivos para as probabilidades, como aquela que aqui foi explorada, as tarefas que partem das probabilidades para os conetivos têm a vantagem de implicar, necessariamente, o recurso aos conetivos para poder resolver essas tarefas.

\section{Agradecimentos}

Este trabalho contou com o apoio de Fundos Nacionais através da FCT - Fundação para a Ciência e a Tecnologia no âmbito do projeto PEst-OE/CED/UI1661/2014, do CIEd-UM e do projeto UID/Multi/04016/2016.

\section{Referências}

ALVES, M. P.; FERNANDES, J. A. Alterações do programa de matemática do ensino básico português: o caso do tema Organização e Tratamento de Dados. Olh@ res, Guarulhos, v. 3, n. 1, p. 280-305, 2015.

BATANERO, C. La comprensión de la probabilidad en los niños: ¿qué podemos aprender de la investigación? In: ENCONTRO DE PROBABILIDADES E ESTATÍSTICA NA ESCOLA, 3., 2013, Braga. Proceedings... Braga: Centro de Investigação em Educação da Universidade do Minho, 2013. 
p. $9-21$.

BOROVCNIK, M.; PEARD, R. Probability. In: BISHOP, A. J. ET AL. (Ed.). International handbook of mathematics education. Dordrecht: Kluwer Academic Publishers, 1996. p. 239-287.

CAVALCANTE, J. L.; ANDRADE, V. L. V. X.; RÉGNIER, J. C. O conceito de probabilidade na formação docente: uma reflexão apoiada pela análise estatística implicativa. VIDYA, Santa Maria, v. 36, n. 2, p. 441-455, 2016.

COSTA, A.; NACARATO, A. M. A estocástica na formação do professor de Matemática: percepções de professores e de formadores. Bolema, Rio Claro, v. 24, n. 39, p. 367-386, 2011.

FERNANDES, J. A. O conhecimento de probabilidades de futuros educadores e professores do ensino básico. In: ENCONTRO DE PROBABILIDADES E ESTATÍSTICA NA ESCOLA, 4., 2017, Vila Real. Proceedings... Vila Real: Universidade de Trás-os-Montes e Alto Douro, 2017.

FERNANDES, J. A. Concepções erradas na aprendizagem de conceitos probabilísticos. 1990. 171 f. Dissertação (Mestrado em Educação) - Universidade do Minho, Braga, Portugal, 1990.

FERNANDES, J. A. Intuições e aprendizagem de probabilidades: uma proposta de ensino de probabilidades no $9^{\circ}$ ano de escolaridade. 1999. 461 f. Tese (Doutorado em Educação) - Universidade do Minho, Braga, Portugal, 1999.

FERNANDES, J. A. et al. Comparação de probabilidades de acontecimentos formulados de forma explícita e implícita. REVEMAT, Florianópolis, v.10, n. 2, p. 42-60, 2015.

FERNANDES, J. A. et al. Desempenho em probabilidade condicionada e probabilidade conjunta de futuros professores do ensino básico. Quadrante, Lisboa, v. XXIII, n. 1, p. 43-61, 2014.

FISCHBEIN, E. The intuitive sources of probabilistic thinking in children. 1. ${ }^{a}$ ed. Dordrecht: Reidel, 1975.

FISCHBEIN, E.; SCHNARCH, D. The evolution with age of probabilistic, intuitively based misconceptions. Journal for Research in Mathematics Education, Reston, v. 28, n. 1, p. 96-105, 1997.

GODINO, J. D. Categorías de análisis de los conocimientos del profesor de matemáticas. UNIÓN Revista Iberoamericana de Educación Matemática, La Laguna, n. 20, p. 13-31, 2009.

GODINO, J. D.; BATANERO, C. Significado institucional y personal de los objetos matemáticos. Recherches en Didactique des Mathématiques, Grenoble, v. 14, n. 3, p. 325-355, 1994.

GODINO, J. D.; BATANERO, C.; FONT, V. The onto-semiotic approach to research in mathematics education. ZDM, Berlin, v. 39, n. 1-2, p. 127-135, 2007.

MINISTÉRIO DA EDUCAÇÃO E CIÊNCIA. Programa de matemática para o ensino básico. Lisboa: MEC, 2013.

POLLATSEK, A. et al. Understanding conditional probabilities. Organizational Behavior and Human Decision Processes, Seattle, v. 40, n. 2, p. 255-269, 1987.

SILVA, M. A. A Presença da Estatística e da Probabilidade no currículo prescrito de cursos de Licenciatura em Matemática: uma análise do possível descompasso entre as orientações curriculares para a educação básica e a formação inicial do professor de Matemática. Bolema, Rio Claro, v. 24, n. 40, p. 747-764, 2011. 
TVERSKY, A.; KAHNEMAN, D. Judgment under uncertainty: Heuristics and biases. In: KAHNEMAN, D.; SLOVIC, P.; TVERSKY, A. (Ed.). Judgment under uncertainty: Heuristics and biases. Cambridge: Cambridge University Press, 1982a. p. 3-20.

TVERSKY, A.; KAHNEMAN, D. Causal schemas in judgment under uncertainty. In: KAHNEMAN, D.; SLOVIC, P.; TVERSKY, A. (Ed.). Judgment under uncertainty: Heuristics and biases. Cambridge: Cambridge University Press, 1982b. p. 117-128.

TVERSKY, A.; KAHNEMAN, D. Extensional versus intuitive reasoning: The conjunction fallacy in probability judgment. Psychological Review, Washington, v. 90, n. 4, p. 293-315, 1983.

WATSON, J. M. Conditional Probability: Its place in the mathematics curriculum. Mathematics Teacher, Reston, v. 88, n. 1, p. 12-17, 1995.

WATSON, J. M. The probabilistic reasoning of middle school students. In: JONES, G. A. (Ed.). Exploring probability in school: Challenges for teaching and learning. New York, NY: Springer, 2005, p. 145-169.

WATSON, J. M.; MORITZ, J. B. The development of comprehension of chance language: Evaluation and interpretation. School Science and Mathematics, West Lafayette, v. 103, n. 2, p. 65-80, 2003.

WATSON, J. M.; MORITZ, J. B. School students' reasoning about conjunction and conditional events. International Journal of Mathematical Education in Science and Technology, London, v. 33 , n. 1 , p. 59-84, 2002.

Submetido em 19 de Junho de 2017. Aprovado em 09 de Dezembro de 2017. 